Proceedings

\title{
Changes in the Health-related Quality of Life of Chinese Women in Japan Following the COVID-19 Outbreak
}

\author{
Yunjie Luo ${ }^{1}$ and Yoko Sato ${ }^{2, *}$ \\ 1 Graduate School of Health Sciences, Hokkaido University, Sapporo, Hokkaido 060-0812, Japan; raa@eis.ho- \\ kudai.ac.jp \\ 2 Faculty of Nursing, Hokkaido University, Sapporo, Hokkaido 060-0812, Japan; ys@hs.hokudai.ac.jp \\ * Correspondence: ys@hs.hokudai.ac.jp
}

Publisher's Note: MDPI stays neutral with regard to jurisdictional claims in published maps and institutional affiliations.

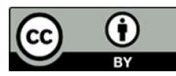

Copyright: (c) 2020 by the authors. Submitted for possible open access publication under the terms and conditions of the Creative Commons Attribution (CC BY) license (http://creativecommons.org/licenses/by/4.0/).

\begin{abstract}
This study aimed to examine the changes in the health-related quality of life (HRQoL) of Chinese women in Japan following the COVID-19. An electronic questionnaire survey was conducted after the COVID-19 outbreak. Using a health survey for Chinese women in Japan that was done before the pandemic compared the changes in HRQoL. HRQoL was evaluated using the SF36v2. The women showed an increased risk of impaired mental health and a decreased risk of impaired physical health. The women demonstrated poor mental health, but emergency prevention measures have given them a chance to rest and improve their physical health.
\end{abstract}

Keywords: mental health; physical health; quality of life; COVID-19; immigrant women

\section{Introduction}

In December 2019, the first case of the novel coronavirus SARS-CoV-2 was reported in Wuhan City in Hubei Province, China. The coronavirus disease 2019 (COVID-19) has since spread rapidly throughout the world. As of December 9, 2020, more than 67 million COVID-19 cases have been confirmed, while more than 1.5 million people succumbed to the disease [1]. To combat the rapid spread of COVID-19, many countries took emergency preventive measures such as lockdowns, keeping social distance, and stay-at-home orders. The Chinese government declared a lockdown from January 23, 2020 and announced stricter testing measures and two-week quarantine measures for people wanting to enter China [2]. This put Chinese citizens who live in other countries in a stressful situation and made returning home challenging.

In Japan, the first COVID-19 case was reported in mid-January 2020 [3]. As of December 6, 2020, the number of infected individuals in Japan exceeded 160,000, while the number of deaths has reached 2,300 [4]. To curb the spread of infections, the Japanese government declared a state of emergency and called on residents to establish a "new lifestyle" based on avoiding the "three Cs" (closed spaces, crowded places, and closecontact setting) and implementing necessary countermeasures such as physical distancing, wearing a mask, and washing hands [5]. Although these measures have proven to be effective in slowing the spread of the disease, they will inevitably have a substantial negative impact on individuals' mental and physical health and well-being [6]. Furthermore, an existing study report that almost $30 \%$ of Chinese citizens experienced mental health problems as a common response to the pandemic; these include anxiety, depression, and self-reported stress [7]. To elucidate the influence of the COVID-19 pandemic on people's physical and mental health, surveys at two points-before and after the phase of the COVID-19-is critical [8]. However, there is a lack of existing research that compares the changes in individuals' health from a point before and after the COVID-19 outbreaks. 
Immigrant Chinese women always encounter difficulties due to vulnerabilities associated with their gender responsibilities and the process of acculturation, which may influence their physical and mental health [9]. A previous study report that immigrant Chinese women in Japan undergo acculturation stress and have a higher risk for mental health disease [10]. Based on these findings, we propose that immigrant Chinese women's quality of life has been even more severely affected by the COVID-19 outbreaks.

This study aims to investigate the changes and the impaired risk of each health domain of the health-related quality of life (HRQOL) of Chinese women living in Japan, using two points of survey data from before and after the COVID-19 pandemic.

\section{Methods}

\subsection{Date Collection}

An online questionnaire survey was conducted to collect data in October 2020 using Qualtrics Survey Software. Participants were recruited online using WeChat, a Chinese multi-purpose messaging social media platform developed by Tencent. Participants who met the following criteria were included: (1) are aged older than 20 years; (2) are women of Chinese nationality and were living in Japan during the COVID-19 pandemic; (3) can speak, read, and understand Mandarin Chinese. To compare the changes in HRQoL before and after COVID-19 outbreaks, a general health survey for immigrant Chinese women in Japan before the pandemic was used. This paper questionnaire survey was done from March to September 2019.

\subsection{Measurement}

HRQoL was evaluated using the 36-Item Short Form Health Survey version 2.0 (SF36v2). A simplified Chinese version of SF-36v2 was used. The SF-36v2 consists of 36 items from eight subscales and measures two dimensions. The eight subscales include physical functioning, role-physical, bodily pain, general health, vitality, social functioning, roleemotional, and mental health. The two dimensions include mental component summary (MCS) and physical component summary (PCS). The PRO CoRE software provided by QualityMetric, Inc. using to calculate the scores. The norm-based T scores was used to calculate the scores of each subscale, having a mean of 50 and a standard deviation of 10 . The scores range from 0 to 100, with a higher score indicating a higher level in that health subscale. The scores less than 47 indicated the risk of impaired functioning in the associated subscale [11].

\subsection{Data Analysis}

All data analyses were conducted using the IBM SPSS Statistics version 26.0. The Mann-Whitney U-test was used to examine the significant changes and chi-squared tests was performed to calculate the odds ratios of each health domain of HRQoL before and after the COVID-19 outbreak. The Cronbach's alpha of each health subscale was calculated. The results are presented as $95 \%$ confidence intervals.

\subsection{Ethics Statement}

This study was approved by the ethical review committee of Hokkaido University, Japan. In both before and after phases, each participant survey approved the informed consents in the study before they completed the questionnaire.

\section{Results and Discussion}

\subsection{Changes in HRQoL before and after the COVID-19 outbreaks}

The before-phrase evaluated 109 study samples and the after-phrase collected 193 study samples. The Cronbach's alpha and changes in each subscale of HRQoL before and after the COVID-19 outbreak are shown in Table 1. After the pandemic, the immigrant 
Chinese women in Japan showed lower scores in role-physical, general health, vitality, social functioning, role-emotional, mental health, and MCS than the American general population's means of 50 scores. Meanwhile, following the COVID-19 outbreak, the women showed significantly negative changes in role-physical $(p=0.005)$, role-emotional $(p=0.001)$, mental health $(p=0.004)$, and mental component summary $(p=0.001)$. And significantly positive changes were observed in bodily pain $(p=0.029)$ and physical component summary $(\mathrm{p}=0.029)$.

Table 1. Changes in HRQoL before and after the COVID-19 outbreaks.

\begin{tabular}{llllll}
\hline \multirow{2}{*}{ Variables } & \multicolumn{2}{c}{ Before $(n=103)$} & \multicolumn{2}{c}{ After $(n=160)$} & \multicolumn{2}{c}{$p$ - } \\
& Cronbach's $\alpha$ & Scores & Cronbach's $\alpha$ & Scores & value \\
\hline Physical Functioning & 0.898 & $53.01( \pm 6.39)$ & 0.833 & $53.91( \pm 5.15)$ & 0.973 \\
Role-physical & 0.911 & $48.17( \pm 8.32)$ & 0.878 & $44.85( \pm 9.60)$ & 0.005 \\
Bodily Pain & 0.885 & $47.85( \pm 10.33)$ & 0.801 & $50.76( \pm 8.94)$ & 0.029 \\
General Health & 0.757 & $47.47( \pm 8.69)$ & 0.813 & $48.37( \pm 10.18)$ & 0.273 \\
Vitality & 0.725 & $49.92( \pm 8.51)$ & 0.866 & $48.68( \pm 10.44)$ & 0.451 \\
Social Functioning & 0.570 & $46.29( \pm 8.43)$ & 0.673 & $45.28( \pm 8.84)$ & 0.494 \\
Role-emotional & 0.928 & $44.61( \pm 10.41)$ & 0.911 & $39.61( \pm 11.54)$ & 0.001 \\
Mental Health & 0.801 & $46.70( \pm 9.37)$ & 0.863 & $42.84( \pm 11.11)$ & 0.004 \\
PCS ${ }^{1}$ & 0.704 & $51.13( \pm 6.78)$ & 0.740 & $53.26( \pm 6.50)$ & 0.029 \\
MCS ${ }^{2}$ & 0.825 & $44.81( \pm 9.71)$ & 0.867 & $40.11( \pm 11.66)$ & 0.001 \\
\hline
\end{tabular}

${ }^{1}$ PCS: physical component summary; ${ }^{2}$ MCS: mental component summary.

Both before and after the outbreak, the mean scores of all the mental health-related subscales (vitality, social functioning, role-emotional, and mental health) and MCS were lower than the means of 50. These results reveal that Chinese women living in Japan generally experience mental health issues. The results share several similarities with an existing systematic review of immigrant Chinese women [9].

This study is the first to examine the changes in HRQoL among Chinese women in Japan before and after the COVID-19 outbreak. The most remarkable result to emerge from the data is the significant negative impact on the mental health-related domains. The impact of COVID-19 on mental health has also been addressed in many studies on various populations [6,12,13]. Although emergency prevention measures had the intended temporary effect on controlling the spread of the COVID-19 epidemic, people's socio-economic activities were exceedingly influenced, leading to increased stress and anxiety. Women, especially, have been more easily affected considering mental health issues than men [14]. With the changes in lifestyle, women are likely to experience a greater psychological impact and develop avoidant behaviors when faced with the COVID-19 pandemic [15].

\subsection{Impaired Risk of Each HRQoL Domain following the COVID-19 Outbreak}

Using chi-squared test the odds ratio was calculated to evaluate the impaired risk of each subscales and domains of HRQoL following the COVID-19 outbreaks, which was shown in Table 2. The women experienced an increased risk of impaired role-physical $(\mathrm{OR}=2.057,95 \% \mathrm{CI}[1.241,3.411], \mathrm{p}=0.006)$, impaired role-emotional $(\mathrm{OR}=2.683,95 \% \mathrm{CI}$ $[1.572,4.580], \mathrm{p}<0.000)$, impaired mental health $(\mathrm{OR}=2.206,95 \% \mathrm{CI}[1.332,3.653], \mathrm{p}=$ $0.002)$, and mental component summary ( $\mathrm{OR}=1.920,95 \% \mathrm{CI}[1.151,3.202], \mathrm{p}=0.013)$. Moreover, there is a decreased risk of impaired physical function $(\mathrm{OR}=0.358,95 \% \mathrm{CI}$ $[0.166,0.775], \mathrm{p}=0.010)$ and physical component summary $(\mathrm{OR}=0.472,95 \% \mathrm{CI}[0.260$, $0.858], \mathrm{p}=0.014)$.

Following the COVID-19 outbreak, the results indicated 2.6 times, 2.2 times, and 1.9 times increase in impaired risk on role-emotional, mental health, and mental component summary, respectively. One reason for Chinese women suffering from mental health impairment may be that women are usually the primary caregivers of their children, and the pandemic resulted in Chinese women in Japan having to work while taking care of their 
children at home. Moreover, another existing study reported that during the COVID-19 pandemic, the residence status of immigrants is a significant risk factor of poor mental health among women [16]. Some Chinese women in Japan are losing their jobs due to the pandemic, which may further increase the impaired risk of mental health. Considering our results, it is clear that the psychological well-being of Chinese women in Japan needs to be addressed and that social support to improve their mental health is necessary.

Table 2. The impaired risk of HRQoL following the COVID-19 outbreaks.

\begin{tabular}{|c|c|c|c|c|c|c|}
\hline \multirow{2}{*}{$\begin{array}{l}\text { HRQoL subscales and } \\
\text { domains }\end{array}$} & \multirow{2}{*}{$\begin{array}{c}\text { Before } \\
(n=103)\end{array}$} & \multirow{2}{*}{$\begin{array}{c}\text { After } \\
(n=160)\end{array}$} & \multirow{2}{*}{$\mathrm{OR}^{1}$} & \multicolumn{2}{|c|}{$95 \%$ Confidence Interval } & \multirow{2}{*}{$X$} \\
\hline & & & & lower & upper & \\
\hline \multicolumn{7}{|l|}{ Physical Functioning } \\
\hline$\geq 47$ & 84 & 148 & 0.358 & 0.166 & 0.775 & 0.010 \\
\hline$<47$ & 19 & 12 & & & & \\
\hline \multicolumn{7}{|l|}{ Role-physical } \\
\hline$\geq 47$ & 64 & 71 & 2.057 & 1.241 & 3.411 & 0.006 \\
\hline$<47$ & 39 & 89 & & & & \\
\hline \multicolumn{7}{|l|}{ Bodily Pain } \\
\hline$\geq 47$ & 52 & 96 & 0.680 & 0.413 & 1.120 & 0.161 \\
\hline$<47$ & 51 & 64 & & & & \\
\hline \multicolumn{7}{|l|}{ General Health } \\
\hline$\geq 47$ & 49 & 93 & 0.654 & 0.397 & 1.076 & 0.101 \\
\hline$<47$ & 54 & 67 & & & & \\
\hline \multicolumn{7}{|l|}{ Vitality } \\
\hline$\geq 47$ & 59 & 85 & 1.183 & 0.718 & 1.948 & 0.528 \\
\hline$<47$ & 44 & 75 & & & & \\
\hline \multicolumn{7}{|l|}{ Social Functioning } \\
\hline$\geq 47$ & 58 & 93 & 0.929 & 0.563 & 1.531 & 0.799 \\
\hline$<47$ & 45 & 67 & & & & \\
\hline \multicolumn{7}{|l|}{ Role-emotional } \\
\hline$\geq 47$ & 46 & 37 & 2.683 & 1.572 & 4.580 & $<0.000$ \\
\hline$<47$ & 57 & 123 & & & & \\
\hline \multicolumn{7}{|l|}{ Mental Health } \\
\hline$\geq 47$ & 60 & 62 & 2.206 & 1.332 & 3.653 & 0.002 \\
\hline$<47$ & 43 & 98 & & & & \\
\hline \multicolumn{7}{|l|}{$\mathrm{PCS}^{2}$} \\
\hline$\geq 47$ & 73 & 134 & 0.472 & 0.260 & 0.858 & 0.014 \\
\hline$<47$ & 30 & 26 & & & & \\
\hline \multicolumn{7}{|l|}{$\mathrm{MCS}^{3}$} \\
\hline$\geq 47$ & 48 & 50 & 1.920 & 1.151 & 3.202 & 0.013 \\
\hline$<47$ & 55 & 110 & & & & \\
\hline
\end{tabular}

Since 2006, the Japanese government has developed the Multicultural Coexistence Promotion Plan to support the adaptation process for immigrant residents [17]. Among these plans, many regions in Japan provide livelihood support for immigrant women, including interpretation services, childcare seminars, and child-rearing seminars. However, due to the COVID-19 pandemic, all the events have been suspended. The lack of necessary social activities may be another noteworthy reason for the impact on immigrant Chinese women's mental health. Therefore, we suggest that the government needs to provide more social support during these extraordinary times for immigrant women to improve their mental health, such as online child-rearing courses or seminars.

Another result showed significant positive changes and decreased impaired risk of physical health-related domains. Interestingly, this study presented an improvement in physical health-related subscales and domain after the COVID-19 outbreak. A previous 
study reported that the population of mainland China showed the highest practice of preventative measures, compared with other countries [18]. Our study confirmed that not only people from mainland China but also immigrant Chinese present a high awareness of the prevention of physical health problems. Similar to the dual positive and negative consequences of the COVID-19 pandemic and lockdown measures on the environment [19], the HRQOL of immigrant women was positively and negatively impacted by the pandemic.

There are, of course, some limitations that might have influenced the results of this study. First, given the sample size, caution must be exercised. In addition, selection bias may occur. As the after- phase data were collected online, the age of the study sample was significantly younger than that of the before phase. Furthermore, the study sample of the before and after phases are not the same participants. Further investigations using longitudinal studies using the same sample would be preferable.

\section{Conclusions}

This study investigated the negative changes in role-physical, role-emotional, mental health, mental component summary, and the positive changes in bodily pain and physical component summary. Increasing impaired risk in mental health-related domains and decreased impaired risk in physical health-related domains were presented. Following the COVID-19 outbreak, Chinese women in Japan experienced poor mental health and a high impaired risk of functioning due to mental health problems. However, prevention measures against the COVID-19 pandemic give them a chance to rest at home to improve their physical health.

Author Contributions: Y.L. and Y.S.; methodology, Y.L..; software, Y.L. and Y.S.; validation, Y.L. and Y.S.; formal analysis, Y.L.; investigation, Y.L.; resources, Y.L.; data curation, Y.L.; writingoriginal draft preparation, Y.L. and Y.S.; writing - review and editing, Y.L. and Y.S.; visualization, Y.S.; supervision, Y.S.; project administration. All authors have read and agreed to the published version of the manuscript.

Funding: The research received no external funding.

Acknowledgments: The authors would like to thank all the participants in the study and to extend appreciation to the staff that allowed data collection.

Conflicts of Interest: The authors declare that there are no conflicts of interest.

\section{References}

1. World Health Organization. Available online: https://covid19.who.int/table (Accessed on: December 11, 2020).

2. Chinazzi, M.; Davis, J.T.; Ajelli, M.; Gioannini, C.; Litvinova, M.; Merler, S.; Pastore Y Piontti, A.; Mu, K.; Rossi, L.; Sun, K.; Viboud, C.; Xiong, X.; Yu, H.; Halloran, M.E.; Longini, I.M.; Vespignani, A. The Effect of Travel Restrictions on the Spread of the 2019 Novel Coronavirus (COVID-19) Outbreak. Science 2020, 368 (6489), 395-400.

3. Shimizu, K.; Negita, M. Lessons Learned from Japan's Response to the First Wave of COVID-19: a Content Analysis. Healthcare 2020, $8(4), 426$.

4. Japanese Mistry of Health, Labour and Welfare. Available online: https://www.mhlw.go.jp/stf/covid-19/kokunainohasseijoukyou.html (Accessed on: December 10, 2020).

5. Basic Policies for Novel Coronavirus Disease Control by the Government of Japan. Available online: https://www.mhlw.go.jp/content/10900000/000634753.pdf (Accessed on December 11, 2020).

6. Galea, S.; Merchant, R.M.; Lurie, N. The Mental Health Consequences of COVID-19 and Physical Distancing: the Need for Prevention and Early Intervention. JAMA Intern. Med. 2020, 180 (6), 817-818.

7. Rajkumar, R.P. COVID-19 and Mental Health: A Review of the Existing Literature. Asian J. Psychiatr. 2020, $52,102066$.

8. Holmes, E.A.; O’Connor, R.C.; Perry, V.H.; Tracey, I.; Wessely, S.; Arseneault, L.; Ballard, C.; Christensen, H.; Cohen Silver, R.C.; Everall, I.; Ford, T.; John, A.; Kabir, T.; King, K.; Madan, I.; Michie, S.; Przybylski, A.K.; Shafran, R.; Sweeney, A.; Worthman, C.M.; Yardley, L.; Cowan, K.; Cope, C.; Hotopf, M.; Bullmore, E. Multidisciplinary Research Priorities for the COVID-19 Pandemic: a Call for Action for Mental Health Science. Lancet Psychiatry 2020, 7 (6), 547-560.

9. Chen, J.; Cross, W.M.; Plummer, V.; Lam, L.; Tang, S. A Systematic Review of Prevalence and Risk Factors of Postpartum Depression in Chinese Immigrant Women. Women Birth 2019, 32 (6), 487-492.

10. Jin, Q.; Mori, E.; Sakajo, A. Risk Factors, Cross-Cultural Stressors and Postpartum Depression among Immigrant Chinese 
Women in Japan. Int. J. Nurs. Pract. 2016, 22 (Suppl. 1), 38-47.

11. Maruish, M.E. User's Manual for the SF-36v2 Health Survey, 3rd ed.; Quality Metric Incorporated: Lincoln; pp. 73-75.

12. Kikuchi, H.; Machida, M.; Nakamura, I.; Saito, R.; Odagiri, Y.; Kojima, T.; Watanabe, H.; Fukui, K.; Inoue, S. Changes in Psychological Distress during the COVID-19 Pandemic in Japan: a Longitudinal Study. J. Epidemiol. 2020, 30 (11), $522-528$.

13. Hazarika, M.; Das, S.; Bhandari, S.S.; Sharma, P. The Psychological Impact of the COVID-19 Pandemic and Associated Risk Factors during the Initial Stage among the General Population in India. Open J. Psychiatry Allied Sci. 2021,12 (1), 31-35.

14. McGuine, T.A.; Biese, K.M.; Petrovska, L.; Hetzel, S.J.; Reardon, C.; Kliethermes, S.; Bell, D.R.; Brooks, A.; Watson, A.M. Mental Health, Physical Activity, and Quality of Life of US Adolescent Athletes during COVID-19-Related School Closures and Sport Cancellations: A Study of 13000 Athletes. J. Athl. Train. 2020.

15. Rodríguez-Rey, R.; Garrido-Hernansaiz, H.; Collado, S. Psychological Impact of COVID-19 in Spain: Early Data Report. Psychol. Trauma 2020, 12 (5), 550-552.

16. Liang, P.; Wang, Y.; Shi, S.; Liu, Y.; Xiong, R. Prevalence and Factors Associated with Postpartum Depression during the COVID-19 Pandemic among Women in Guangzhou, China: a Cross-Sectional Study. B.M.C. Psychiatry 2020, 20 (1), 557.

17. Japanese Mistry of Health, Labour and Welfare. Available online: https:/www.soumu.go.jp/menu_news/s-news/01gyosei05_02000138.html (Accessed on: December 14, 2020).

18. Zhao, B.; Kong, F.; Aung, M.N.; Yuasa, M.; Nam, E.W. Novel Coronavirus (COVID-19) Knowledge, Precaution Practice, and Associated Depression Symptoms among University Students in Korea, China, and Japan. Int. J. Environ. Res. Public Health 2020, $17(18), 6671$.

19. Patrício, S.A.L.; Prata, J.C.; Walker, T.R.; Duarte, A.C.; Ouyang, W.; Barcelò, D.; Rocha-Santos, T. Increased Plastic Pollution Due to COVID-19 Pandemic: Challenges and Recommendations. Chem. Eng. J. 2021, 405, http://www.ncbi.nlm.nih.gov/pub$\mathrm{med} / 126683$. 